\title{
CAIXEIRAS DO DIVINO: PERFORMANCE FEMININA E SUA INTER- RELAÇÃO COM O SAGRADO
}

\author{
Marcelle Schleinstein Achilles da ROCHA
}

\begin{abstract}
RESUMO
As Caixeiras do Divino compõem um grupo de mulheres com raízes afrodescendentes que tocam tambor ritual na tradicional Festa do Divino Espírito Santo de Alcântara no Maranhão. Seu objetivo é propagar os ensinamentos de toques de caixa para as próximas gerações, além de realizar o ritual sagrado da Festa do Divino Espírito Santo sob a forma de obrigação espiritual. Apesar de as Caixeiras não se autodenominarem artistas, o trabalho que elas desempenham com sua gestualidade, danças e cânticos, ficando horas em pé a tocar tambor ritual, faz delas sujeito e objeto de sua própria arte, arte esta que se traduz como uma espécie de ritual de evocação ao Divino. As Caixeiras, que são uma singularidade das Festas do Divino no Maranhão, possuem forte ligação não só com os terreiros, mas também com o território de origem, que está atrelado à figura feminina. É por meio de suas performances que se inicia o espaço-tempo do Divino. São as Caixeiras que fazem todo o ritual de início do sagrado. Os rituais que as Caixeiras realizam ao tocar caixa e cantar para o Divino são a tradução do simbolismo do sagrado.
\end{abstract}

Palavras-chave: Caixeiras; Performance; Terreiros; Simbolismo; Sagrado.

CAIXEIRAS OF DIVINE: FEMALE PERFORMANCES AND THE RELATIONSHIP WITH THE SACRED

\section{ABSTRACT}

The Caixeiras of Divine make up a group of women of African descent roots that play ritual drum in the traditional Feast of the Holy Spirit of Alcântara, in Maranhão (Brazil). Your goal is to propagate the teachings of ritual drum for the next generations, and perform the sacred ritual of the Feast of the Holy Spirit in the form of spiritual obligation. Although the Caixeiras do not call themselves artists, the labor they play with their gestures, dances and songs, getting hours standing playing ritual drum makes them subject and object of his own art, an art that translates as a sort of ritual invocation of the Divine. The Caixeiras, which are a singularity of Divine celebrations in Maranhão, have strong connection not only with the terreiros (place where the rituals for Candomble and other Afro-Brazilian religions take place) but also to the country of origin, which is related to the female figure. It is through their performances that begins the Divine spacetime. They are the Caixeiras who do all of the holy ritual.The rituals that Caixeiras perform when they play ritual drum and sing to the Divine are the translation of the sacred symbolism.

Keywords: Caixeiras; Performace; Terreiros; Symbolism; Sacred.

\section{CAIXEIRAS DEL DIVINO: PERFORMANCE FEMENINA Y SU INTER-RELACIÓN CON EL SAGRADO}

\section{RESUMEN}

Las Caixeiras del Divino componen un grupo de mujeres con raices afrodescendientes que tocan tambor ritual en la tradicional Fiesta del Divino Espíritu Santo de Alcántara, en Maranhão (Brazil). Su objetivo es propagar las enseñanzas de toques de tambor ritual para las próximas generaciones, además de realizar el ritual sagrado de la Fiesta del Divino Espíritu Santo bajo la forma de obligación espiritual. A pesar de que las Caixeiras no se autodenominan artistas, el trabajo que ellas desempeñan con su gestualidad, danzas y cánticos, quedando horas en pie a tocar el tambor ritual hace de ellas sujeto y objeto de su propio arte, arte que se traduce como una especie de ritual de invocación de lo Divino. Las Caixeiras, que son una singularidad de las Fiestas del Divino en Maranhão, poseen fuerte conexión no sólo con los terreros (lugar donde los rituales de las religiones afrobrasileñas
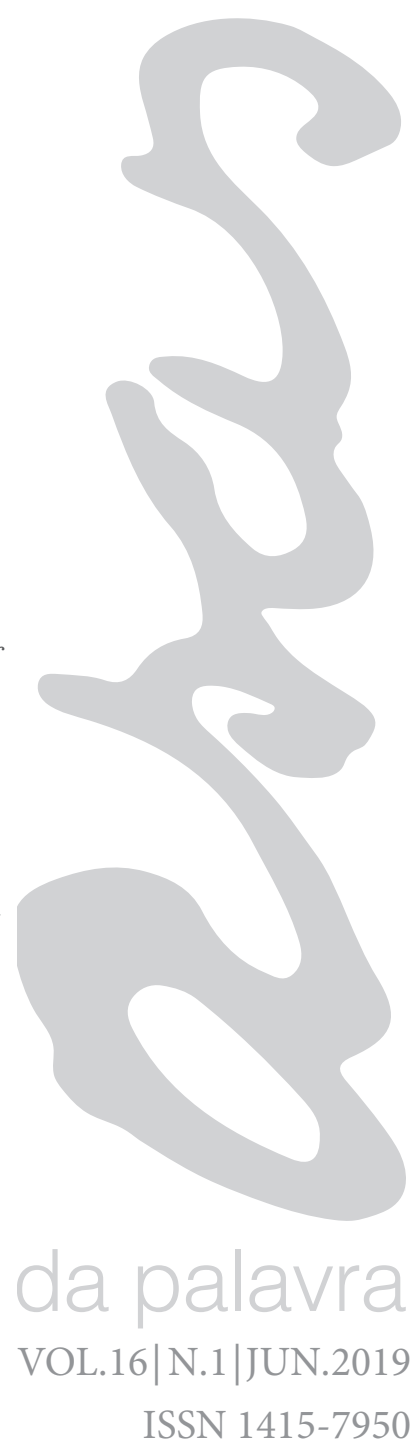
ocurren), sino también con el territorio de origen, que está vinculado a la figura femenina. Es por medio de sus performances que se inicia el espacio-tiempo del Divino. Son las Caixeiras que hacen todo el ritual de inicio de lo sagrado. Los rituales que las Caixeiras realizan al tocar tambor ritual y cantar para lo Divino son la traducción del simbolismo de lo sagrado.

Palabras clave: Caixeiras; Performance; Terreiros; Simbolismo; Sagrado.

\section{INTRODUÇÃO}

O percurso dessa investigação acadêmica teve início em 2013, quando atuava na Assessoria de Comunicação do Serviço Social do Comércio (Sesc). Proveniente da área da Comunicação, especificamente do Jornalismo, tive a oportunidade de conhecer um projeto musical gratuito idealizado pelo Sesc chamado Sonora Brasil. Criado em 1998, o Sonora Brasil tem por objetivo contribuir com o processo de democratização da informação musical qualificada, promover valores culturais e identidades, e permitir o acesso a programações voltadas ao aumento do nível de cultura musical de seus espectadores. Ele cria identificações em um cenário de músicas tradicionais, provando que não existe uma ruptura entre a tradição e a modernidade, e, sim, reformas do discurso de gosto musical.

O Sonora Brasil busca selecionar artistas que representam a música popular regional após criteriosa pesquisa, realizada pelos técnicos da área de música, na qual uma votação é feita entre todos os técnicos que atuam em todos os departamentos regionais do Sesc, com a finalidade de selecionar o tema que irá ser trabalhado e qual artista o representará. Com o tema Sagrados mistérios: vozes do Brasil, o Sesc convidou, em 2011, um grupo de mulheres para excursionar pelo país mostrando, sob a forma de cânticos, as rezas que homenageavam o Espírito Santo e que representavam a cultura maranhense. Estas mulheres, conhecidas como Caixeiras do Divino, compõem um grupo com raízes afrodescendentes que toca tambor ritual na tradicional Festa do Divino Espírito Santo de Alcântara, no Maranhão.

O objetivo das Caixeiras é propagar os ensinamentos de toques de caixas para as próximas gerações, além de realizar o ritual sagrado da Festa do Divino Espírito Santo sob a forma de obrigação espiritual. A performance que elas desempenham possui não somente um domínio artístico, mas também - e muito fortemente - um domínio da cultura, pois sua performance recobre um aspecto "étnico e intercultural, histórico e a-histórico, estético e ritual, sociológico e político" (SCHECHNER, 2002, p. 199). Segundo Glusberg (1987), a performance incorpora aspectos individuais e sociais, sendo o artista sujeito e objeto de sua arte. Existem duas conotações para performance: a que indica "uma presença física e a outra um espetáculo, no sentido de algo para ser visto" (1987, p. 43). Os performers, por vezes, costumam utilizar o próprio corpo tanto para exaltar suas qualidades plásticas, quanto para medir sua resistência e energia. Mesmo com essa ligação direta com o corpo, a performance ainda assim mantém conexões com o social. Apesar de as Caixeiras não se autodenominarem artistas, o trabalho que elas desempenham com sua gestualidade, danças e cânticos, ficando horas em pé a tocar tambor ritual, faz delas sujeito e objeto de sua própria arte, arte esta que se traduz como uma espécie de ritual de evocação do Divino.

A Festa, que não ocorre sem a presença das Caixeiras, é toda marcada pelos cânticos que são entoados por estas mulheres, que vão puxando e rimando os versos nesta celebração repleta de simbologia. A Festa do Divino é um dos poucos rituais onde quem toca são as mulheres (já que, no Maranhão, a Festa está associada aos terreiros e, geralmente, nos terreiros os instrumentos são tocados pelos homens, por isso a singularidade das Caixeiras no âmbito da Festa do Divino). A elas cabe a missão de eternizar o ritual da cerimônia e o 
conhecimento musical da Festa.

As Caixeiras, que são uma singularidade das Festas do Divino no Maranhão, possuem forte ligação não só com os terreiros: Tambor de Mina, mas também com o território de origem, que está atrelado à figura feminina. Conforme dito por algumas devotas durante a pesquisa de campo, a força feminina era muito presente na cultura maranhense, tanto que nas entrevistas elas mencionaram uma figura muito importante no cenário político do Maranhão e que atendia pelo nome de Ana Jansen, nobre senhora proveniente da Europa e dona de escravos, segundo relato das próprias Caixeiras. A esta personagem são atribuídas algumas lendas no território maranhense, mas a sua relevância na política do Maranhão acabou se refletindo também na Festa do Divino, o que possivelmente influenciou outras mulheres, dando origem à presença das Caixeiras na celebração do Divino e, também nos terreiros. Segue um diálogo entre as devotas a respeito da importância da presença feminina no Maranhão e, logo a seguir, uma definição de terreiro "Tambor de Mina", por Ferretti (2006):

Claudia: Essa coisa da Caixeira é muito forte na Festa do Maranhão. É uma coisa tradicional no Maranhão. É que lá é uma Festa comandada por mulheres, elas estão à frente de tudo. E aqui [na Casa do Maranhão-RJJ também. A gente faz aqui como se faz lá. (Claudia Brito, maranhense, devota do Divino e frequentadora da Casa do Maranhão, no Rio de Janeiro. Mãe da mordoma-régia de 2017)

Marcia: Isso é uma coisa muito interessante, aí você vê como o matriarcado, lá [no Maranhão], é muito forte, porque a Festa do Divino é o Tambor de Mina, que é comandado por mulheres na Casa das Minas, na Casa de Nagô... E o tambor é dançado por mulheres... É uma força muito grande, apesar de ser uma sociedade machista. A força das mulheres está na elaboração das coisas. A gente fala da Ana Jansen, mas Ana Jansen foi uma mulher importante. Foi uma mulher que não casou, não teve filho... (Marcia Mochel, maranhense, também devota do Divino, é Caixeira da Casa do Maranhão, no RJ)

Claudia: Era uma mulher temida. Muitas lendas no Maranhão ligadas a ela.

Marcia: Era uma mulher temida. Uma líder politica, que tinha uma força enorme! Era dona de vários escravos, dizem que era uma mulher má, mas também tem muito mito em torno... Ela era uma mulher de muita força, uma mulher que mandava em tudo quanto é homem. A Ana Jansen era politica, mandava na política do Maranhão. Os terreiros de lá foram fundados por mulheres vindas da África.

Tambor-de-Mina, ou simplesmente Mina, é uma denominação da religião afrobrasileira surgida no Século XIX, na capital maranhense, onde continua sendo hegemônica. Além de muito difundida no Pará, é encontrada em outros Estados do Norte e do Nordeste e em grandes cidades brasileiras (como Rio de Janeiro, São Paulo, Brasília) para onde foi levada principalmente por migrantes do Maranhão e do Pará. Na Mina as entidades espirituais africanas são genericamente denominadas "voduns", o que mostra a influência recebida da Casa das Minas, terreiro jeje fundado em São Luís por membros da família real do Daomé, considerado o mais antigo. [...] O terreiro mais antigo, a Casa das Minas [...] é de origem daomeana. Nele são tocados três tambores de uma só membrana, só se entra em transe com vodum e se canta a noite toda em língua fon. O outro, também fundado por africanas, é a Casa de Nagô. Nele são tocados dois tambores de duas membranas, suspensos sobre cavaletes - os abatás -, são recebidos e cultuados voduns e orixás, gentis (entidades nobres, como Dom Luís), caboclos, e se canta principalmente em lingua africana. (FERRETTI, 2006, p. 90-92)

Ildenir: Porque a Mina vem de uma cidade da África chamada Daomé, então, esses escravos dessa cidade desembarcaram no Mara- 
nhão, no porto, e lá eles fundam o terreiro de Mina pra relembrar a religião deles. Depois eles vão fundar na Bahia, que é a Casa de Jeje, aí tem os voduns que, no candomblé, são os orixás... Eu encaro os voduns como orixás. Eles não misturam, eles fazem aquela parte da África deles só de orixá, quando entra o encantado aí já mistura, ai já não sei muito como a coisa acontece. E na Casa das Minas tinha a parte da encantaria, o encantado seria como um mensageiro dessa parte dos voduns, que fala, que traz o recado, né? O vodun não falava, ele transmitia as mensagens. No final, misturou com encantaria... Hoje as duas Casas acabaram [Casa das Minas e Casa de Nagô] porque ninguém mais foi iniciado. Hoje, no Maranhão, tem candomblé, ai eles dizem que é Mina, mas não é bem assim não. Casa das Minas hoje só festeja Festa do Divino e Bumba meu boi. [O pai de santo José de Itaparandi] tem um terreiro de Mina... Ele preserva, mas com algumas diferenças, não é como era Casa das Minas e como era Casa de Nagô, porque você vai se adaptando ao moderno, né? Tem o vodun, tem o encantado, tem outras coisas... [Ele] preserva, mas não é a raiz como deveria ser. (Ildenir Freitas, coordenadora de projetos da Casa do Maranhão, maranhense radicada no $R J$ desde a década de 50)

Mudanças ocorreram não só nos terreiros, mas também no próprio território maranhense. Por volta da década de 1950, mudanças políticas no Brasil fizeram com que muitos maranhenses migrassem para outras regiões do país, principalmente para o Rio de Janeiro, onde fundaram a Casa do Maranhão, um centro cultural idealizado pela Colônia Maranhense que vive no Rio de Janeiro e que será apresentada com mais detalhes logo a seguir. E foi na Casa do Maranhão (RJ) onde se deu o nosso estudo de campo com as Caixeiras e as performances rituais que elas realizam.

\section{O ESPAÇO-TEMPO DO DIVINO}

A Festa do Divino Espírito Santo é uma celebração tradicional do calendário cristão e tem início 50 dias após a Páscoa. A Festa homenageia a terceira pessoa da Santíssima Trindade, o Espírito Santo, e envolve dezenas de devotos. Todo o ritual que envolve a Festa chega a durar 15 dias em média, podendo variar dependendo da região. A Festa do Divino é dividida em quatro etapas (mas pode haver outras conforme a localidade). Em geral, ela engloba a Abertura da Tribuna, o Levantamento do Mastro, Pentecostes e a Derrubada do Mastro. Com o tempo, algumas etapas foram suprimidas devido a diversos fatores - financeiros ou de ordem pessoal - e tiveram de ser reconfiguradas e adaptadas à realidade de cada região.

A Festa compreende o movimento, representando o presente e o futuro, transmitindo aos seus devotos o significado de constante transformação e adaptação a que todos os indivíduos estão sujeitos (BARBOSA, 2012). O ritual da Festa tem por característica certa flexibilidade, as coisas não são fixas, elas são adaptáveis, e onde houver um maranhense devoto do Divino é provável que haja também uma Festa para celebrá-lo. Foi dessa identificação com o território de origem e a devoção ao Divino que a Festa teve início em outras regiões do Brasil.

Nos anos 1950 um número significativo de maranhenses deixou sua terra natal e migrou para o sudeste do Brasil, e foi seguindo o rastro desses migrantes que chegamos à Casa do Maranhão, no Rio de Janeiro. A Casa do Maranhão é uma espécie de centro cultural que visa a promover encontros entre maranhenses e perpetuar as raízes históricas de sua cultura, bem como realizar a Festa do Divino Espírito Santo na capital carioca. A peculiaridade da Festa do Divino realizada pela Casa do Maranhão está no fato de que ela não é realizada em um terreiro e, sim, em um clube chamado ASCAER (Associação dos Servidores Civis da Aeronáutica), no bairro da Ilha do Governador. A Casa

VoL. 16 | N.1 | JUN. 2019 do Maranhão foi fundada no dia 10 de setembro de 2011, mas antes disso, o 
fundador da Colônia Maranhense no Rio de Janeiro, seu Manoel Colaço, já realizava a Festa do Divino na cidade desde o ano de 1967.

\begin{abstract}
Ildenir: Ele [Manoel Colaço] era pai de santo e ele que fundou, no dia 16 de maio de 1967, a Festa do Divino aqui no Rio. [...] Essa Festa foi fundada por esse pai de santo que morava no Parque União. Mas ela é fundada por uma pessoa do povo, simples, ele tinha bons contatos e dizem que era muito bom pai de santo. Alcione frequentava a casa dele, várias personalidades maranhenses frequentavam, então, a primeira Festa foi um sucesso. E foi muitos anos até ele ir embora...
\end{abstract}

A Festa do Divino Espírito Santo realizada pela Casa do Maranhão teve de passar por algumas adaptações, pois o clube da ASCAER é alugado e, sendo assim, duas etapas passaram a ser realizadas em um único dia: a Abertura da Tribuna e o Levantamento do Mastro. Todas as etapas são minuciosamente preparadas e executadas pelos devotos. O comprometimento com a Festa costuma ser motivado por algum agradecimento ou pelo pagamento de promessas. Cada uma dessas etapas da celebração envolve o ritual das Caixeiras, que rezam e tocam; seus cânticos servem para exaltar o Espírito Santo.

A expressão artística das Caixeiras do Divino ocorre quando se dá o diálogo entre o espaço cênico com todos os elementos que são significantes de uma sagração simbólica - objetos, vestimentas, crianças representando o Império - e a performance dessas devotas que cantam e dançam para o Divino. São as Caixeiras que fazem todo o ritual de evocação do sagrado. É por meio de suas performances que se inicia o espaço-tempo do Divino. Suas performances operam sob a tríade arte-corpo-comunicação, na qual os protagonistas são o sujeito, o corpo e o tempo, e onde cada elemento é manifestamente artístico (GLUSBERG, 1987). Pode-se dizer que na performance das Caixeiras o corpo se faz como escultura viva, pois deixa antever que estas senhoras que tocam caixa há tantos anos são a arte em si mesmas, permitindo aos devotos contemplarem sua força e sua energia.

Embora os rituais ocorram no pátio externo e no salão interno do clube ASCAER, o centro - que é onde o mastro ${ }^{1}$ é erguido - recolhe sua eficácia enquanto templo do Divino, fazendo a transição de um espaço profano para o sagrado. "Todos esses fenômenos que significam a passagem do espaço profano ao espaço sagrado - limiares, portões, pontes, caminhos, escadas, cordas e outros - atestam uma inscrição do sagrado em um nível de experiência sob essa língua" (RICOEUR, 1995, p. 50). O mesmo pode ser dito do tempo, que dispensa qualquer tipo de linguagem pré-verbal, e dá início a um tempus que é heterogêneo, pois ele cria uma cisão entre o tempo dos homens para dar início ao tempo do Divino. O ritual da Festa interrompe não só o tempo profano como também o espaço, promovendo um período em que os devotos se aproximam dos deuses e "a eficácia do ser se revela dentro da densidade do tempo" (RICOEUR, 1995, p. 50).

Os rituais que as Caixeiras realizam ao tocar caixa e cantar para o Divino são a tradução do simbolismo do sagrado, o ritual atesta sua eficácia. Conforme Ricoeur (1995), o sagrado manifesta-se por meio de signos e comportamentos significativos, sendo assim, parte das manifestações, inclusive dos modos de agir dos devotos e das Caixeiras - as roupas utilizadas, a etiqueta no modo como os devotos se referem aos símbolos do Divino, a hierarquia, as danças, os cânticos, os gestos de devoção - refletem a essência desse sagrado, cujas trocas e mudanças de nível acontecem o tempo todo.

As Caixeiras possuem uma função social dentro do ritual, não se trata de pessoas descompromissadas ou sem entrosamento com o restante do grupo. Seus papéis são bem determinados e elas conhecem suas obrigações, enquanto representantes da Colônia Maranhense e residentes no estado do
1 Este mastro, feito de tronco de árvore, geralmente eucalipto, simboliza o início do tempo do Divino, ele separa o tempo profano do tempo sagrado. É quando ocorre a conexão do céu com a Terra. Enquanto ele está em pé na ASCAER significa que os devotos estão a vivenciar o tempo do Espírito Santo. Quando ele é derrubado, isso quer dizer que o tempo sagrado foi interrompido para ser retomado no ano seguinte. 
Rio de Janeiro. Sua função social está no resgate de uma tradição que é típica do estado do Maranhão, e, portanto, elas têm por "missão" reforçar e defender suas origens, enquanto cidadãs maranhenses; e há também o sentimento de dever para com o Divino enquanto fiéis, e é este "dever" que regula todo o modus operandi das ações e funções sociais das Caixeiras durante a Festa. O Divino se manifesta por meio do ritual musical das Caixeiras e opera situações de milagre que somente um devoto do Divino é capaz de experienciar, é por isso que a Festa do Divino é tão importante para os maranhenses da Casa do Maranhão, que a celebram há tantos anos no Rio de Janeiro.

A Festa é o que dá sentido àqueles devotos, especialmente às Caixeiras que, mesmo fora do período da Festa, continuam tocando em outras localidades do país, inclusive dão aulas de caixa e de ladainha (apesar de serem mães, avós, esposas e filhas no dia-a-dia), ou seja, sua constituição, enquanto devotas, está atrelada a uma sequência de eventos em que se desagregar e reconstituir-se faz com que elas sejam quem são: guardiãs dos mistérios do sagrado.

\title{
ETAPAS DA FESTA E PERFORMANCES RITUAIS
}

A primeira etapa do ritual de evocação do Divino e conexão com o sagrado começa com a Abertura da Tribuna. Nesta etapa, as crianças se vestem com roupa normal, elas não usam capotes (mantos), vestidos e nem fardas, pois a atenção é voltada para os objetos reais (coroa, pomba e cetro) que serão finalmente alocados em seus devidos lugares em um pequeno altar que fica sobre um tablado. As Caixeiras cantam e tocam em todas as etapas da Festa. Seus cânticos são parte fundamental do ritual e permitem transmutar e atribuir poder à encenação realizada pelo Império, representado pelas crianças, dotando-o de efeitos místicos. A eficácia é garantida por conta de sua própria encenação em conjunto com as melodias que as Caixeiras entoam e seus batuques, gerando uma espécie de transe. Nenhuma ação é realizada sem a performance ritual das Caixeiras, é como se elas detivessem a permissão do Divino para a realização do ritual que dá início à transmutação de tempo/templo profano em tempo/ templo sagrado. Em Peirano (1973) podemos acompanhar uma investigação a respeito da eficácia que se dá por meio do ato performativo das Caixeiras.

\begin{abstract}
Como esta analogia tem força convencional, ela é a base da ação ritual que pode, então, ser classificada, segundo Austin (1962) como um "ato performativo" - isto é, ele produz resultados em virtude de ser realizado. Assim, atos rituais não são apenas "representações", mas eles têm um propósito que se "realiza" através de um mecanismo analógico de eficácia simbólica. (PEIRANO, 1993, p. 3)
\end{abstract}

Passado o dia de Aleluia, vem a segunda etapa do ritual, o Levantamento do Mastro, mas que na Casa do Maranhão será feito no mesmo dia da Abertura da Tribuna pelo fato de não ser um terreiro e, sim, um clube. O mastro, geralmente, é um tronco de eucalipto, que é enfeitado e depois batizado.

Gercy: Minha mãe eu ouvia dizer que ia até de barco [pegar o mastro].
Um pau enorme que eles tiram de dentro do mato, virgem, que não foi
usado pra nada. Isso lá no Maranhão! Aí vinha as Caixeiras tocando,
tinha música, mocotó, aquela feijoada para aquele dia, aí na quinta-
-feira da ascensão levantava o mastro, aí eles fincam ou raspam, bota
murta, coco, cana, banana, aí fica tudo arrumadinho, vinho e bota a
bandeira lá em cima e a gente canta. (Gercy de Oliveira, Caixeira-ré-
gia. Está na Colônia desde a sua fundação no Rio de Janeiro)

Depois que o mastro é batizado, as Caixeiras continuam cantando e tocando enquanto ele é posto de pé. Os devotos passam a tocar no mastro como se este fosse uma espécie de objeto santo, dotado de poderes milagrosos. Ainda segundo Peirano (1973), os rituais são comportamentos que fogem ao comportamento padrão e que se utilizam de representações simbólicas como 
validador da conduta ritual. Além disso, a comunicação utilizada dentro de um ritual é uma comunicação estruturada e que segue uma linguagem própria. Podemos dizer que Festas religiosas são um comportamento comum em diversas sociedades, porém, a Festa do Divino pode ser vista como um ritual na medida em que combina Caixeiras que tocam para evocar o Divino; um mastro que é batizado e preparado para a celebração; o Império representado por crianças; objetos como pomba, coroa e cetro etc. Todos estes elementos fazem da Festa uma reunião de símbolos que ajudam na comunicação com o Espírito Santo e validam a sacralidade do ritual.

Após o levantamento, um jantar é oferecido, primeiramente, às crianças do Império; as Caixeiras cantam e tocam durante toda a refeição do Império. Elas só se sentam para jantar quando o Império todo termina de comer. Em seguida, o jantar é servido aos demais devotos. Muitas das Caixeiras que encontramos na Casa do Maranhão receberam a missão de tocar caixas como herança de alguma mulher na família que já tocava também, ou seja, a arte de tocar este instrumento acaba acontecendo de maneira natural, sem uma intervenção mais incisiva da própria candidata à Caixeira, que perpetua os mistérios dessa arte como missão espiritual, passada de geração em geração. Pode-se dizer que o ofício destas Caixeiras se traduz como um comportamento restaurado (SCHECHNER, 2006, p. 8). Um "comportamento restaurado" pelos rituais é como dizer que uma pessoa desempenha uma determinada performance simplesmente porque ela aprendeu que deve ser assim.

\begin{abstract}
Colocando em palavras próprias, o comportamento restaurado "sou eu me comportando como se fosse outra pessoa", ou "como me foi dito para fazer", ou "como aprendi". Mesmo se me sentisse completamente como sou, atuando independentemente, apenas um pouco de investigação revelaria que as unidades de comportamento que contém meu "eu" não foram por "mim" inventadas. (SCHECHNER, 2006, p. 8)

Gercy: [Comecei a tocar caixa no Maranhão] desde os 13 anos. $O$ meu pai fez uma caixinha. [...] Eu, como já conhecia do Maranhão, já tava casada, ai eu comecei também a ajudar a Vitória [Caixeira-régia da Casa do Maranhão que está aposentada] porque Vitória era Caixeira-régia da minha mãe... Ai nós pegamos aquela amizade. Eu era bem garota. [...] Quando aquele moço ali [aponta para quadro de Manoel Colaço] inaugurou a dele, não tinha Caixeira ai eu fui lá nessa casa que ele criou, ele tinha um terreiro e ai ele começou a fazer essa Festa e eu fui ajudar.
\end{abstract}

Este comportamento restaurado, como dito por Schechner (2006), no âmbito da Festa, permite aos devotos e às Caixeiras explorar suas múltiplas personas, isso inclui o transe e o papel de cavalo $^{2}$ que algumas Caixeiras experimentam no momento em que elas dão início ao ritual. Algumas Caixeiras, por possuírem forte ligação com os terreiros e entidades espirituais, que elas chamam de encantados, acabam por se conectar com o lado místico da Festa, e podem experienciar essa outra personalidade que thes é característica, por meio do comportamento restaurado, dado que este comportamento inclui algumas ações que consistem "de porções recombinadas de comportamentos previamente vivenciados" (SCHECHNER, 2006, p. 9); ou seja, mesmo o dever espiritual de algumas Caixeiras para com o Divino já fora vivenciado antes mesmo de iniciado o ofício como Caixeira. Isso se deve aos laços que estas mantêm com o lado místico da Festa, que envolve a encantaria.

Ildenir: Ele [o encantado] já vem te acompanhando quando você nasce. Você já é escolhida pra ser o corpo que ele vai utilizar. Não é querer. E tem gente que gosta, quer e acontece de pegar, mas, especificamente, o encantado é muito pra essa região do Maranhão, Pará,

\section{Cavalo é o nome dado à pessoa que recebe entidades espirituais (encantados).}


Amazonas, mas o grande forte do encantado é o Maranhão. Maranhão cultua muito a encantaria. [...] Ele [o encantado] vem na dona Antônia. Ele é muito normal. Você não diferencia uma pessoa da outra, no caso, o cavalo do encantado. Ele bebe, ele come, ele é uma pessoa normal. Mas seu Légua tá sempre na dona Antônia na Festa. Ela [a pessoa que recebe o encantado] já vem escolhida, não é você querer. [...] Quase todo mundo [tem ligação com encantado]! A dona Vitória mesmo, ela não gosta, mas o encantado dela pegava ela no grande dia da Festa. Vitória já não era mais Vitória. Falando, você já conhecia que não era mais Vitória. Vitória era a nossa Caixeira-régia.

Dona Antônia da Costa é uma das Caixeiras mais antigas na Casa do Maranhão, além de tocar caixa, é também mãe de santo e possui um terreiro Tambor de Mina, em Nova Iguaçu. Por herança da mãe, ela também realiza a Festa do Divino em seu terreiro desde a década de 1970, no Rio de Janeiro. Dona Antônia mudou-se para o Rio de Janeiro ainda menina e, quando sua mãe faleceu, viu-se na obrigação de assumir não só os rituais do terreiro, mas também os da Festa do Divino Espírito Santo. Sua celebração ocorre no mês de julho, quando a Festa do Divino já aconteceu na Casa do Maranhão. Dona Antônia tem como encantado a entidade conhecida como Légua Bogi Buá, é ele quem guia os trabalhos de dona Antônia durante a Festa e, é seu Légua também o patrono da Festa do Divino na Casa do Maranhão.

Embora algumas Caixeiras da Casa do Maranhão tenham dado os primeiros passos no fazer da Festa do Divino nos terreiros de Mina do Maranhão, elas se identificam como católicas. Algumas delas tocam em Festas realizadas em terreiros no Rio de Janeiro, mas ainda assim elas se identificam como católicas. Isso, na Casa do Maranhão, ou seja, para estas Caixeiras, a Festa do Divino que elas celebram é católica, assim como sua religião e, portanto, os devotos se identificam com a Festa do Divino da Casa do Maranhão por esta representar certa "neutralidade", já que esta não é realizada nem no terreiro e nem mesmo na igreja, atraindo pessoas de diversas crenças. Esse sincretismo na Festa do Divino Espírito Santo já foi objeto de estudo de alguns autores, Ferretti (1995, p. 105), por exemplo, afirma que:

Todas as religiões são sincréticas, são frutos de contatos culturais múltiplos, mas todas se julgam puras, perfeitas e não se querem misturadas com outras que seriam impuras. Em nossa sociedade o sincretismo é mais discutido, principalmente em relação às religiões afro-brasileiras, consideradas religiões sincréticas por excelência, por terem sido formadas no Brasil com a inclusão de elementos de procedências africanas, ameríndias, católicas e outras.

O que ocorre é um fato curioso, pois mesmo crendo ser uma Festa católica a que é realizada pela Casa do Maranhão, os próprios devotos não abrem mão da participação das Caixeiras, que é uma tradição tipicamente da Festa do Divino Espírito Santo dos terreiros de Mina do Maranhão. Isso significa dizer que, mesmo aderindo à tradição de origem católica, os devotos da Casa do Maranhão apegam-se ao toque das Caixeiras, o que os conecta a uma identidade particular que é só deles, enquanto maranhenses. As Festas do Divino estão muito ligadas à identidade de seus devotos, criando uma diferença e uma singularidade, que destaca esses devotos e os insere em uma identidade que é singular, proporcionando uma identidade maranhense, ou seja, uma identidade da diferença. Além de resgatar identidades, o que a Festa faz é perpetuar experiências de uma mesma coletividade, além das promessas de vida e pactos celebrados entre devotos e o Espírito Santo.

Após a Abertura da Tribuna e o Levantamento do Mastro, ocorre a terceira etapa do ritual: Pentecostes, que é considerada a principal etapa da Festa do Divino, é a que mais requer dedicação, pois é onde ocorre a missa, a coroação do Império na igreja, a procissão, almoço e a ladainha feita pelas

Caixeiras. É quando o Império, vindo da procissão, finalmente assume o trono na Tribuna. Atualmente, a missa é realizada na Igreja de Santa Rita de Cássia, 
no centro do Rio de Janeiro, mas já passou por diversas outras igrejas, cujos padres não aceitavam a celebração com tamanha receptividade. Nessa paróquia, as Caixeiras têm permissão para tocar dentro da Igreja. A coordenadora da Casa do Maranhão, Ildenir Freitas, conta-nos que o padre da Igreja de Santa Rita é um admirador da Festa do Divino Espírito Santo e aceitou com satisfação o convite para celebrar a missa do Divino, já que os devotos vinham passando por experiências frustrantes em relação à convivência dos padres com as Caixeiras durante a missa. Além de ser uma festa popular, a Festa do Divino Espírito Santo da Casa do Maranhão passa a ser também uma festa de resistência.

Ildenir: A gente vai em igrejas que [...] aceitem o tipo da Festa que é, porque nós fazemos a missa, nós pagamos uma missa... e nessa igreja, que é de Santa Rita de Cássia, aqui na [Rua] Visconde de Inhaúma, nós descobrimos o padre... Fico muito emocionada porque a primeira missa do Divino aqui no Brasil foi realizada na Igreja de Santa Rita de Cássia e ele se apaixonou pela questão... Ele agora faz questão que a missa seja celebrada lá [...]. Ele [...] deixa que as Caixeiras façam os rituais delas dentro da igreja, que não acontecia em outras igrejas, e é muita emoção! Essa Festa aqui do Divino é uma Festa de resistência!

Depois da missa realizada na Igreja de Santa Rita de Cássia, há a entrega de donativos para uma instituição de caridade e o Império das crianças segue para a ASCAER. Chegando à ASCAER, na rua em frente, o Império, as Caixeiras, a banda e os devotos seguem em procissão até a entrada do clube; a bandeira do Divino segue à frente, logo atrás vem o Império e depois as Caixeiras tocando e cantando, seguidas dos devotos. Durante o ritual, as Caixeiras rezam por meio de suas caixas e cânticos para saudar a terceira pessoa da Santíssima Trindade, o Espírito Santo. Ao entrarem no clube todos dão três voltas ao redor do mastro. O três, fortemente ligado ao ritual, é um número simbólico ligado à mediação do tempo nas mais antigas culturas e que foi apropriado ao longo dos séculos por algumas religiões.

A própria Bíblia católica revela a existência de três Marias que receberam o anúncio da ressurreição de Cristo. Conforme o livro de Marcos (16-1-11), eram Maria Madalena, Maria Cleófas e Maria Salomé, ratificando a mística do número três. Também a Santíssima Trindade, da qual o Espírito Santo é a terceira pessoa, infere que o três está relacionado a essa medição do tempo e à expectativa de um retorno. Após este ritual, que dura em torno de uma hora, as crianças do Império seguem para um almoço que é preparado na cozinha do clube pelos componentes da Colônia Maranhense, que se doam em prol do Espírito Santo. Enquanto as crianças almoçam, as Caixeiras ficam em torno da mesa tocando sem parar, até que o último integrante do Império termine sua refeição. Somente após o Império terminar de comer e se levantar é que as Caixeiras podem almoçar, bem como os demais participantes da Festa. Este é o momento em que todos deixam um pouco a sua obrigação de lado para apreciar a Festa, conversar com os amigos, dançar e descansar. Às dezoito horas, as Caixeiras se reúnem para tocar a melodia final, chamada de Alvorada, como uma aclamação ao Divino e angústia pelo fim do dia $^{3}$.

A cerimônia de Derrubada do Mastro, última etapa do ritual, significa não só o fim da Festa, mas também o fim de um tempo, o tempo do Divino. Muitos devotos se emocionam neste dia, pois o Divino se vai e durante um ano ele fica "interrompido" para retornar no ano seguinte. A celebração tem início às 18 horas da segunda-feira, após Pentecostes (domingo). O ritual começa com as Caixeiras cantando e tocando para o Divino. Este é também o dia em que o trono é passado para o novo imperador e a nova imperatriz. Assim como no dia da Abertura da Tribuna, na derrubada do mastro as crianças do Império também são as primeiras a iniciar as refeições.

3 Alvorada/ Minha amiga foliã/ Me diga que horas são/ Se já deu Ave Maria/ Eu quero tomar bênçã̃o/ Ave Maria já deu/ Ave Maria está dando/ Meu Divino Espírito Santo/ Nos botai vossa bênção/ É seis horas, é seis horas/ Hora de Cristo rezar/ Maria traz o tapete/ Pros anjos se ajoelhar/ Já se vai o belo dia/ Já se vem a triste noite/ Meus senhores e senhoras/ Deus vos dê uma boa noite/ Boa noite, boa noite/ Boa noite nos dê Deus/ Salvação pra nossa alma/ Graças pra servir a Deus/ Já se vai o sol embora/ Deixando o mundo sem luz/ Aí peço que não me deixe/ Sem a chaga de Jesus/ O sol posto tá doente/

Se não sangra ele morre/ $\mathrm{O}$ sol posto é como sangue/ Que por toda veia corre.

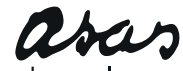

da palavra 
As Caixeiras tocam e só param quando a última criança termina de comer. Após todos jantarem, começa uma procissão rumo ao mastro, que fica no pátio da ASCAER. Durante a derrubada, o Império e alguns devotos batem com um pequeno machado três vezes no mastro fazendo três pedidos. Esta machadada significa a interrupção cósmica entre o céu e a Terra, que somente será retomada no próximo ano.

A Festa realizada pela Casa do Maranhão é um ritual onde alguns devotos possuem um vínculo espiritual, mas isso não significa que eles não se divirtam, isto é, a parte da obrigação está no momento em que cada um está a executar a tarefa que lhe fora incumbida, como é o caso das Caixeiras que, durante os cânticos, ficam muito concentradas, algumas até entram em transe por conta da proximidade dos encantados. Mas, quando elas param de tocar, sentam-se juntas para comer algo e neste momento elas se descontraem, dão risadas e alegram-se por estarem tocando e reencontrando os amigos, pois a Festa do Divino Espírito Santo é parte de um ritual onde elas se identificam enquanto devotas e enquanto maranhenses.

\section{CONSIDERAÇÕES FINAIS}

Vivemos de rituais sagrados desde o momento em que nascemos até o momento em que morremos, de modo que parece impossível separar determinados eventos cotidianos da sacralidade que nos cercam. É como se, ao separá-los, o mundo se tornasse banal. É possível imaginar a Festa do Divino sem os seus objetos e sem as Caixeiras? Sendo estes tão importantes para o ritual, parece impossível separar uns e outros, já que eles se ligam ao sagrado pelo ritual que gira em torno deles, reforçando laços e identidades.

A Festa do Divino é uma celebração que se mostra rica, porém, difícil de ser trabalhada, pois, quando se adentra o mundo do sagrado, ficamos a buscar palavras para descrever o ritual e não encontramos. As Caixeiras e os devotos maranhenses possuem estreita ligação aos terreiros de Mina do Maranhão porque se trata de algo bastante comum na vida familiar deles. A Festa os conecta com algo que vai além da explicação. Mesmo tendo os encantados para direcioná-los para as obrigações espirituais que eles possuem, eles preferem se identificar aos católicos; o terreiro e a incorporação são tratados com discrição tanto pelas Caixeiras, quanto pelos devotos.

Ao longo das visitas que fizemos à Casa do Maranhão, durante as diversas oficinas de caixa e de ladainha - que ocorrem ao longo do ano para preparar novas Caixeiras do Divino -, observamos dos bastidores que aquele espaço, a Casa do Maranhão, funciona como uma espécie de centrum que conecta estes maranhenses que vieram das mais diversas regiões do Maranhão e ali se encontram e se reconhecem como parentes distantes. São pessoas que fazem da Festa o seu próprio existir, já que eles passam o ano inteiro a se preparar para a Festa, em especial as Caixeiras, que dirigem todo o ritual. Os rituais das Caixeiras visam não somente exaltar o Espírito Santo, fazer promessas e agradecer, mas também partilhar um mundo extrassensível, onde os devotos executam tarefas em comum e dividem momentos e lembranças que são as experiências de um com as experiências de outro.

Como pudemos observar, o ritual da Festa do Divino se traduz em um sistema cultural que é praticado nos terreiros de Mina do Maranhão e funciona como um meio de comunicação simbólico entre os indivíduos que partilham dessa comunicação enquanto imigrantes maranhenses. Podemos englobar a atuação das Caixeiras como um sistema de performance que diz algo a respeito desse ritual cuja Festa permite aos devotos experimentar um canal de comunicação com o sagrado e os situa segundo valores que são inferidos durante a performance da Festa. A performance das Caixeiras, ou seja, a ação ritual permite sacralizar os objetos da Festa (a pomba, o mastro, a VOL. 16 | N.1 | JUN. 2019 coroa e o cetro) e dotá-los de certa eficácia simbólica. 
Embora tentemos, por vezes, afastar-nos desse mundo místico, o fato é que a existência humana está atrelada à crença no sagrado. À medida que vamos vivendo em um mundo repleto de tecnologia e avanços no campo científico, vamos também nos distanciando do mundo do sagrado, cujos templos tornaram-se descartáveis. Porém, mesmo que a ciência avance nas discussões sobre a origem do mundo, ainda assim resquícios de um mundo místico insistirão em permanecer e a Festa do Divino Espírito Santo, com suas Caixeiras como guardiãs dos mistérios sagrados, permite aproximar os devotos desse mundo místico, instalando a heterogeneidade do espaçotempo, rompendo com o ordenamento instituído pelo nosso cotidiano.

\section{REFERÊNCIAS}

BARBOSA, Marise. Umas mulheres que dão no couro: as Caixeiras do Divino no Maranhão. São Paulo: Empório de Produção e Comunicação, 2006.

BRITO, Viviane. Mulheres que tiram joias da caixa: tradição do Maranhão tocada pelas Caixeiras do Divino no Rio de Janeiro. 2014. 102 f. Dissertação (Mestrado em Estudos Contemporâneos das Artes) - Instituto de Arte e Comunicação Social, Universidade Federal Fluminense, Rio de Janeiro, 2014.

FERRETTI, Sérgio Figueiredo. Repensando o sincretismo: estudo sobre a Casa das Mina. São Paulo: Editora da Universidade de São Paulo; São Luís: FAPEMA, 1995.

"Festa do Divino no Maranhão". In: Catálogo da Exposição Divino Toque do Maranhão. Rio de Janeiro: Centro Nacional de Folclore e Cultura Popular/ IPHAN/ MEC. p. 9-29, 2005.

“Sincretismo e religião na Festa do Divino". In: Revista Anthropológicas, ano 11, volume 18(2). p. 105-122, 2007.

GLUSBERG, Jorge. A arte da performance. São Paulo: Perspectiva, 1987.

RICOEUR, Paul. Figuring the sacred: religion, narrative and imagination. Minneapolis: Fortress Press, 1995.

SCHECHNER, Richard. Performance studies, an introduction. London: Routledge, 2002.

. "What is performance?". In: Performance studies: an introduccion, second edition. New York \& London: Routledge, p. 28-51, 2006.

VAN GENNEP, Arnold. Os ritos de passagem. Petrópolis: Vozes, 1978.

\section{ANEXO I APRESENTAÇÃO DAS DEVOTAS ENTREVISTADAS}

1) Ildenir de Oliveira Freitas: entrevista realizada em setembro de 2016. Coordenadora de projetos da Casa do Maranhão. Nasceu no Maranhão, em 1945, e se mudou para o Rio de Janeiro ainda na década de 1950. Atualmente, coordena as oficinas que ocorrem na Casa e ajuda a organizar eventos culturais que servem para angariar fundos para a Festa do Divino.

2) Gercy Sá Oliveira: entrevista realizada em outubro de 2016. Caixeirarégia da Festa do Divino. Nasceu no Maranhão, em 1935, e é casada com 
o presidente da Casa do Maranhão, seu Elesbão Oliveira. Integra a Colônia Maranhense no Rio de Janeiro desde a sua criação, em 1967.

3) Claudia Brito: entrevista realizada em janeiro de 2017. Claudia é mãe da atual mordoma-régia. Maranhense, também é devota do Divino. Todos os anos ela se envolve nos preparativos da Festa, inclusive na parte de artesanato, que está muito presente na decoração da Festa.

4) Marcia Mochel: entrevista realizada em fevereiro de 2017. É professora, nasceu no Maranhão, integra o conjunto de Caixeirasde-linha da Festa do Divino Espírito Santo. Frequenta as oficinas de caixa com outras Caixeiras. Participa dos encontros de artesanato que ocorrem na Casa do Maranhão com o intuito de ajudar nos preparativos da Festa.

Recebido em 25 Mar 2019 | Aprovado em 07 Jun 2019

Marcelle Schleinstein Achilles da ROCHA

Mestre em Cultura e Territorialidades pelo Programa de Pós-Graduação em Cultura e Territorialidades (PPCULT), do Instituto de Artes e Comunicação Social da Universidade Federal Fluminense (UFF). Graduada em Comunicação Social - habilitação Jornalismo, pela Universidade da Cidade - RJ. Associada ao grupo de pesquisa Artesanias, corpos e paisagens (CNPq). E-mail: marcelle.achilles@gmail.com. 